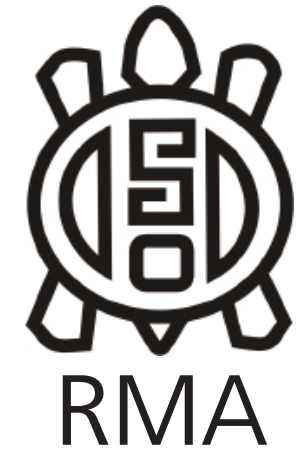

Arqueología

\section{El Camino del Inca en la Cuesta de Zapata (Catamarca, Noroeste argentino)}

\author{
Inca Road on the Zapata Slope (Catamarca, Norwestern Argentina)
}

Reinaldo A. Moralejo*

*División Arqueología, Museo de La Plata. CONICET. Facultad de Ciencias Naturales y Museo, Universidad Nacional de La Plata, Argentina.E-mail: reinaldomoralejo@yahoo.com.ar

\title{
Resumen
}

En este artículo se presenta un análisis micromorfológico de las nuevas evidencias materiales halladas recientemente en un segmento de camino incaico localizado en el sector meridional de la sierra de Zapata (provincia de Catamarca, NO argentino) conocido como Cuesta de Zapata. Asimismo, se realiza un análisis macromorfológico que permite pensar que este camino constituyó para los incas uno de los principales circuitos internodales de interacción regional del centro-oeste catamarqueño. Si bien este camino fue mencionado en anteriores publicaciones, nunca se habían realizado estudios en profundidad tendientes a relevar sus rasgos constructivos y sitios asociados. Por esta razón, estos trabajos además de significar la continuidad de las investigaciones en la zona también representan una revisión de los estudios previamente realizados. La metodología se basó en un abordaje micro y macromorfológico tendiente a relevar aspectos particulares y holísticos del camino relacionados con su rol dentro de la red vial regional. Hasta el momento los resultados de las investigaciones señalan la presencia de diferentes tipos de asentamientos con determinadas características arquitectónicas, modo de instalación, materiales recuperados y relación con el entorno. El circuito de movilidad internodal en esta sierra se extiende desde -por lo menos- el Período Temprano hasta la actualidad.

Palabras clave: redes viales; estudio internodal; sierra de Zapata; micro y macromorfología de caminos.

\begin{abstract}
This article introduces a micro-morphological analysis of new material evidence recently found in a section of the Inca road that is located on the southern section of the Zapata hill (Catamarca Province, Northwestern Argentina) known as Cuesta de Zapata (Zapata Slope). We also performed a macro-morphological analysis, which lead us to think that this road was one of the main inter-nodal Inca circuit of regional interaction in central-west Catamarca. Even though this road was mentioned in previous papers, deeper studies aiming to gather information on its construction and the sites associated to it were not conducted before. Therefore, this research not only continues previous investigations in this area but also is meant to revise them. Methodology was based on micro and macromorphological analyses aiming to survey particular and holistic aspects of the road related to its role within the regional road network. The results so far are showing the presence of different types of settlements with certain kinds of architectonic features, facilities, recovered materials and relationship with the environment. Mobility routes internodal on this hill date from - at least- the Early Period to present times.
\end{abstract}

Keywords: road networks; internodal study; Zapata hill; road micro and macromorphology.

Los caminos constituyen una de las tantas evidencias materiales con las que cuenta la arqueología para comprender el comportamiento humano en el pasado. Los ritmos de la vida social, los sistemas de producción y comunicación se expresan a través de los caminos (Earls, 1979), de modo que su estudio no solo se remite a su condición física sino también a los diversos aspectos simbólicos que le dan vida. Ello hace que pensemos a los caminos como espacios constitutivos de toda sociedad que permiten generar interrelaciones y significados sociales con una identidad propia (González Godoy, 2017).

Para los incas los caminos eran verdaderos símbolos de poder que operaban como una bandera debido a su gran visibilidad y a la forma clara con la que vinculaban al individuo con la autoridad central (Hyslop, 1984). 
Constituían la expresión tangible de la organización espacial andina. Su origen en la región andina se remonta a las épocas de sociedades preincaicas muy complejas como Moche, Wari y Tiwanaku. Los incas se encargaron luego de reutilizarlos y resignificarlos, como también de construir nuevas vías de acuerdo a sus intereses políticos, religiosos y económicos. Muchos de estos caminos continúan en vigencia en la actualidad, por supuesto con otros actores, discursos y prácticas políticas, pero demostrando aún su importancia como elementos de interacción social. Consideramos que su estudio es importante para comprender la diversidad de los procesos sociales que caracterizan a los pueblos que los construyeron, transitaron y significaron.

En este artículo presentamos el registro material de un segmento de camino incaico recientemente relevado en la Cuesta de Zapata -sector S de la sierra de Zapataprovincia de Catamarca, NO argentino (NOA). Este segmento vial forma parte de una antigua ruta o circuito de interacción que atraviesa longitudinalmente la sierra de Zapata y une el valle de Hualfín y el campo de BelénAndalgalá (centro de Catamarca) con los valles de Las Lajas y Abaucán o Fiambalá (O de Catamarca). Aquí el término ruta se usa como equivalente de itinerario o derrotero de un viaje, por lo que representa una categoría abstracta o intangible. En este sentido, siguiendo algunos lineamientos planteados por Berenguer, Cáceres, Sanhueza y Hernández (2005), una ruta podría contar con una o varias vías de comunicación y tráfico correspondientes a la misma o diferente época.

Si bien esta ruta por la sierra de Zapata ya ha sido mencionada por Strube Erdmann (1958, 1963), González (1966), Raffino (1995) y Raffino, Moralejo y Gobbo (2008) como parte del denominado "camino de la Sierra", no se habían realizado hasta el momento investigaciones en profundidad que implicaran recorrer el territorio adoptando un enfoque internodal focalizado en los propios espacios de circulación (Berenguer, 2004; Nielsen, 2006). Es por ello que comenzamos con el estudio micromorfológico de la traza correspondiente a la Cuesta de Zapata en pos de destacar sus técnicas constructivas, la presencia de sitios asociados y relacionarlo con la red vial conocida para la región. En un trabajo anterior se comunicaron brevemente los primeros resultados de un estudio preliminar realizado sobre esta traza (Moralejo, 2018). En esta oportunidad daremos a conocer nuevas evidencias producto de recientes investigaciones de campo que permiten ampliar la información existente.

Vale destacar que este trabajo representa una continuidad y revisión de los estudios viales que venimos realizando en la sierra de Zapata desde fines del siglo XX (Moralejo, 2009, 2011; Raffino, Alvis, Manzo y Toddere, 1994; Raffino, 1995; Raffino et al., 2008). La ruta por esta sierra permite conectar como dijimos más arriba los valles del centro y del o catamarqueño, donde se erigen dos grandes instalaciones incaicas como El Shincal de Quimivil y Watungasta, respectivamente. Por un lado, El Shincal de Quimivil-localizado al S del valle de Hualfín, departamento de Belén, sobre el piedemonte de la serranía del Shincal-, fue considerado un Nuevo Cusco, lo que significa que reunía características arquitectónicas, de asentamiento, mobiliares y paisajísticas muy singulares que replicaban simbólicamente la capital del Tawantinsuyu (Farrington, 1999; Raffino, 1991). Por otro lado, Watungasta emplazado en el sector medio del valle de Abaucán o Fiambalá, departamento de Tinogasta, sobre la confluencia con la quebrada del río La Troya-, funcionó como un centro de manufactura cerámica de alcance regional (Orgaz y Ratto, 2013). Ambos se establecieron como centros políticos, administrativos y ceremoniales incas del NO argentino y constituyeron fuertes nodos camineros de gran importancia para la interacción interregional.

Dada la relevancia de ambos centros nodales, resulta sustancial poner énfasis en los espacios intermedios de interacción interregional, a partir de la investigación del registro arqueológico generado en las propias rutas por diversas prácticas de circulación (Berenguer, 2004; Berenguer y Pimentel, 2010, 2017; Martel, Zamora y Lépori, 2017; Nielsen, 2006; Pimentel, Ugarte, Gallardo, Blanco y Montero, 2017). Este tipo de estudio arqueológico internodal implica, como veremos luego, desarrollar una metodología exhaustiva de registro con el propósito de contribuir a la reconstrucción sistemática del sistema vial de la región. En este sentido, se adopta una perspectiva de la Arqueología del Paisaje que a diferencia de las nociones capitalistas y economicistas, busca entender el espacio como una construcción histórica y social más integral producto de una relación dialéctica entre los humanos, los animales, los objetos y las entidades no humanas. Es decir, el espacio constituye una relación dinámica donde los diferentes agentes despliegan diversas maneras de actuar, influir y provocar efectos (Latour, 2008; Tilley, 1994). A través de los caminos se construye y se expresa la memoria de los pueblos que los transitan, los elaboran y le dan significado a lo largo del tiempo y del espacio. Es por ello que su análisis permite conocer algo más acerca de los actores, discursos y prácticas políticas vinculadas a las rutas o redes de interacción, tráfico e intercambio regional.

\section{Metodología}

Hemos visto como al hablar de caminos, pensamos en el conjunto de elementos del paisaje que le confieren un significado geográfico y ritual que va mucho más allá del simple tránsito. En este sentido, nuestra perspectiva de la Arqueología del Paisaje posee un alcance práctico que se puede entender a partir del conjunto de elementos que conforman el paisaje de manera complementaria: espacio como un medio por el cual se realiza la acción humana y no humana; espacio como un entorno social construido por el ser humano y sus relaciones interpersonales e intercomunitarias; y espacio como un entorno pensado 
o simbólico, que permite comprender la apropiación humana de la naturaleza (Criado Boado, 1999; Latour, 2008). Todo esto indica la necesidad de generar una propuesta metodológica que involucre observaciones y descripciones sobre los aspectos espaciales y formales de las vías de circulación, cada sitio, rasgo o elemento asociado a éstas y los objetos movilizados. Este tipo de abordaje, conocido como análisis micromorfológico de la red vial (Trombold, 1991), es importante para investigar el carácter cronológico y cultural del camino. El reconocimiento de campo implica una estrategia sumamente exhaustiva que exige transitar por la traza vial y hacia ambos lados de la misma, como así también realizar ascensos a lomadas o cerros para obtener una mejor visibilidad del paisaje. Este abordaje se debe complementar con un estudio macromorfológico, orientado a registrar toda aquella información vinculada con la extensión, conectividad, estrategias de movilidad y prácticas asociadas y configuración global del sistema vial (Trombold, 1991).

El acceso a la Cuesta de Zapata donde se localizan los segmentos de caminos que presentaremos en este artículo se puede realizar a través de la actual Ruta Provincial $N^{\circ} 3$ (antiguamente denominada Ruta Nacional $N^{\circ} 40$ ). Se trata de una ruta provincial cuya traza no está pavimentada y debido a diferentes agentes naturales y antrópicos se encuentra en condiciones deplorables para el tránsito vehicular, excepto vehículos pequeños de alta potencia como motocicletas y cuatriciclos. Previamente al trabajo de campo, se realizó un análisis bibliográfico y de documentos históricos tendientes a recopilar toda la información posible, aunque fuera tangencial, acerca de esta antigua ruta (González, 1966; González y Sempé, 1975; Montes, 1959; Raffino, 1995; Raffino et al., 1994, 2008; Sempé, 1973, 1976; Strube Erdmann, 1958, 1963; Vera, 1950; Weiser, 1925-1926). Por otro lado, se elaboró un mapa base con un programa de Sistemas de Información Geográfica que consistió en la digitalización de la traza visible del camino incaico a relevar utilizando la cartografía disponible del Google Earth (Imágenes Quick Birds).

Durante las tareas de campo fue utilizado el mapa base elaborado en gabinete para guiar nuestra prospección pedestre. También se realizaron entrevistas con pobladores locales y se tuvo en cuenta la toponimia local. En cuanto al instrumental de medición, se contó con GPS, brújula Brunton, cámara digital y jalones topográficos.

Los trabajos de prospección se realizaron en sentido NE-SO en base a dos personas, una de ellas caminando por la traza incaica (prospector $n^{\circ} 1$ ) y la otra por la Ruta Provincial $\mathrm{N}^{\circ} 3$ (prospector $\mathrm{n}^{\circ} 2$ ). Esta modalidad permitió que el prospector $n^{\circ} 1$ fuera guiado por el prospector $n^{\circ}$ 2 , teniendo en cuenta que la abundante vegetación -en algunos segmentos del tramo recorrido- dificultaba la visibilidad arqueológica. Esto último también provocó algunos problemas al momento de caracterizar la traza y realizar fotografías.

Con respecto a la terminología empleada en esta investigación, vale subrayar la diferenciación entre trayecto, tramo y segmento vial. Con el término trayecto hacemos referencia a la distancia recorrida por la ruta entre centros nodales como serían en este caso los sitios de El Shincal de Quimivil y Watungasta. El término tramo, en cambio, corresponde a subdivisiones del trayecto encabezadas por determinados sitios, por ejemplo El Shincal de Quimivil - Tambillo Nuevo, Tambillo Nuevo - Río del Inca-Lucke, Río del Inca-Lucke - chaskiwasi Anillaco, chaskiwasi Anillaco - Watungasta. Finalmente, el término segmento corresponde a un intervalo de vía identificable y factible de ser descripto, por ejemplo, los segmentos identificados en la Cuesta de Zapata dentro del tramo Tambillo Nuevo - Río del Inca-Lucke que serán presentados en este artículo.

\section{La antigua ruta por la Cuesta de Zapata}

La sierra de Zapata pertenece al sistema de Sierras Pampeanas Noroccidentales que ocupa el centro y $\mathrm{S}$ de la provincia de Catamarca, y se caracteriza por presentar valles longitudinales y angostos y amplios bolsones rodeados por elevados cordones montañosos. Geológicamente, está compuesta por un basamento precámbrico de metamorfitas y granitos con depósitos terciarios en valles y cuaternarios en las áreas proximales de los piedemontes. La sierra alcanza una altura media de 3000 msnm en el sector $\mathrm{N}$, descendiendo a menos de 2000 msnm en el sector $\mathrm{S}$ donde se encuentra la Cuesta de Zapata. En cuanto a la fisonomía vegetal, prevalece la comunidad del Monte Espinoso perteneciente a la provincia fitogeográfica del Monte (Morláns, 1995). El clima de la región es templado cálido, continental, semiárido característico del NO argentino. Las precipitaciones varían de 150 a 600 mm/año y se caracterizan por ser torrenciales y localizadas durante la temporada estival. Las mayores precipitaciones se presentan sobre la falda oriental de la sierra de Zapata, disminuyendo hacia el S de la misma (González Bonorino, 1972).

El tramo de camino incaico analizado atraviesa el sector meridional de esta sierra y corre dentro de una profunda quebrada, en sentido NE a SO, casi paralelo al lecho de un río de régimen transitorio (Figura 1). Desde la Ruta Provincial $\mathrm{N}^{\circ} 3$ se observa claramente la traza del camino sobre la ladera de la serranía, a unos pocos metros por encima del lecho del río. Se trata de un segmento de $5,27 \mathrm{~km}$ de longitud, cuyo acceso es difícil y sumamente peligroso teniendo en cuenta que hay que descender primero hasta el fondo de la quebrada, y luego volver a subir para dar con su traza (Figura 2). En términos generales se puede decir que este segmento de camino se encuentra en buen estado de conservación. Solo el 
sector correspondiente al portezuelo o abra de la cuesta, como veremos más adelante, se encuentra afectado por la construcción de la antigua Ruta Nacional N 40 y la instalación de una torre de alta tensión.

\section{Características constructivas del camino}

El camino de la Cuesta de Zapata presenta diferentes características constructivas relacionadas con la geografía y con el rol protagónico que tuvo esta ruta en la conexión de los centros nodales de El Shincal de Quimivil y Watungasta.

El camino se desarrolla sobre la ladera natural de la sierra de Zapata sobre una superficie compuesta por rocas, arena, gravas finas a gruesas, guijarros y bloques. La pendiente lateral es pronunciada $\left(35^{\circ}\right)$ por lo que requirió que el lugar de la traza fuera elegido ingeniosamente y el camino construido de manera cuidadosa. Tal es así que los constructores necesitaron incorporar elementos formales de construcción en lugares angostos del camino para favorecer el tránsito. En términos generales el ancho varía de 2 a 4,5 m dentro de la quebrada, y de 5 a $8 \mathrm{~m}$ en los extremos NE y SO por fuera de la quebrada. Esta variación obedece a la topografía, es decir, dentro de la quebrada -cuyo espacio es demasiado estrecho- el camino disminuye su ancho, mientras que por fuera de la misma -donde comienza a adquirir amplitud- el camino se ensancha.

En cuanto a los rasgos estructurales más característicos y recurrentes, hemos identificado la presencia de excavaciones sobre la ladera y el aprovechamiento del material extraído -ya fuera arena, gravas y/o guijarrospara rellenar y nivelar la traza. Este tipo de infraestructura fue combinada con taludes o muros de contención de piedra de 0,75 $\mathrm{m}$ de ancho construidos sobre el borde (Figura 3.a). En algunos segmentos, estos taludes fueron complementados con muros de protección de piedra de 0,50 a $1 \mathrm{~m}$ de altura y que posiblemente fueron utilizados para evitar el derrumbe de piedras ladera abajo y la caída de los animales de carga (Vitry, 2004). Por lo general se los encuentra en caminos con zigzag y pendientes fuertes, como en este caso (Figura 3.b).

Además de los elementos ya mencionados, se detectaron algunos cortes abruptos artificiales sobre la roca de la ladera para delimitar el camino, lo que debió demandar una tarea de ingeniería muy importante; mientras que en otros se aprovechó el perfil natural de las rocas.

En algunos sectores, el camino incaico desciende por razones topográficas hasta el río, e inmediatamente comienza a subir hacia el lado opuesto. Esta situación demandó la elaboración de un diseño en zigzag que permitía descender y ascender rápida y cómodamente por la ladera. El segmento de contacto con la margen del río se presenta bajo la forma de senda con una traza muy poco definida sobre el sustrato. Al mismo tiempo, y en todos los casos donde el descenso se realiza en sectores del río con presencia de grandes bloques rocosos (producto del fuerte gradiente), el punto de contacto entre el camino y el río se genera a través de un vado localizado inmediatamente después de estas abruptas caídas de agua (Figura 4.a). Esto demuestra que el vado no ha sido elegido al azar, sino más bien ha sido producto de un conocimiento profundo de la topografía del paisaje que permitió seleccionar aquellos lugares más efectivos para la localización de la traza. Esta particularidad ha sido observada también

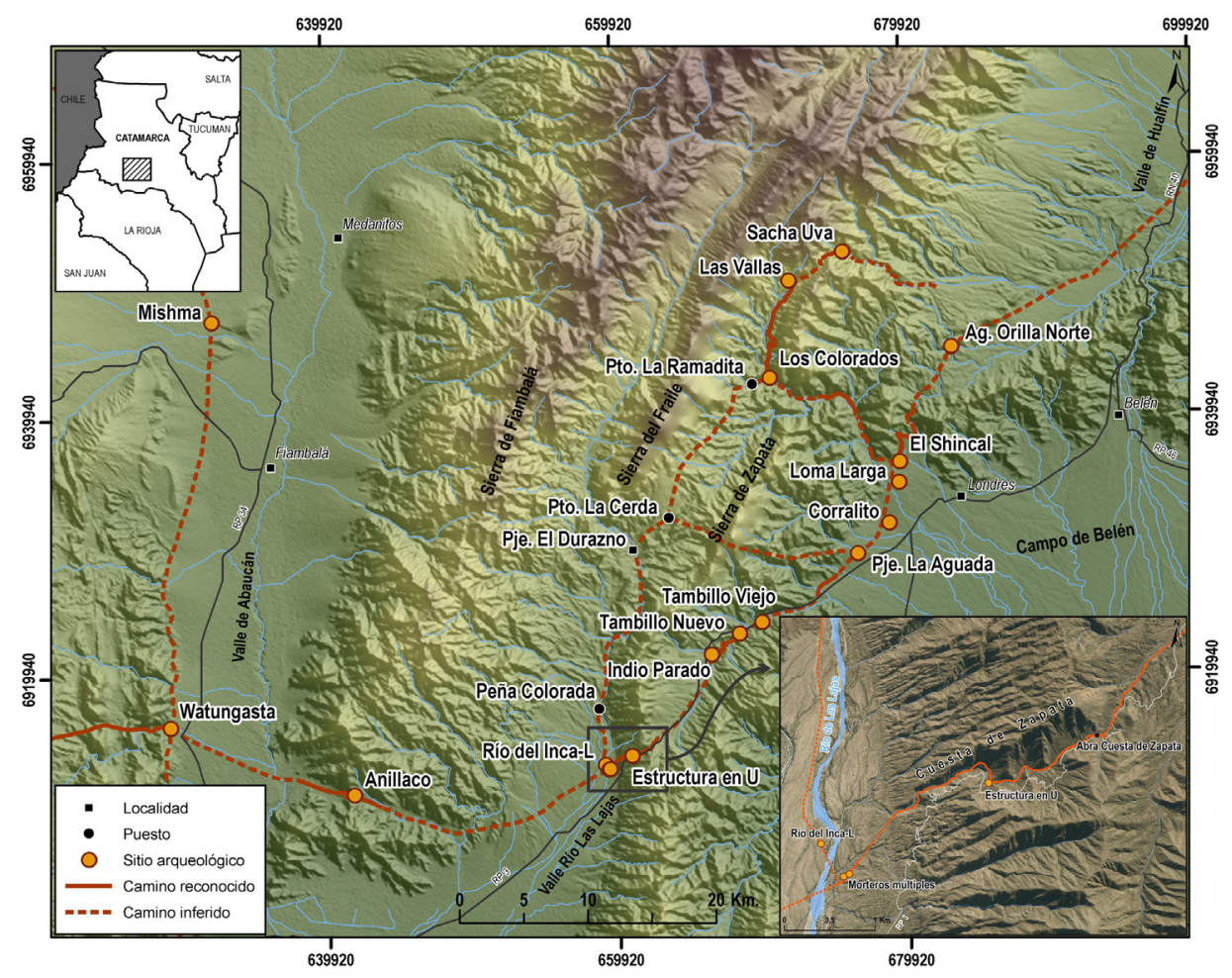
en el tramo que conecta el sitio arqueológico de El Shincal de Quimivil con la Aguada del Norte Chico del departamento de Belén (Moralejo, 2011).

Figura 1. Red vial correspondiente al sur del valle de Hualfín y sierra de Zapata. En la esquina inferior derecha se detalla el segmento estudiado en la Cuesta de Zapata (Coordenadas UTM-19J, Datum WGS84).

Figure 1. Road network from the south of Hualfin valley and Zapata hill. Detail of the studied segment in the Zapata Slope can be been in the lower right corner (UTM-19J, Datum WGS84). 
El empedrado conformado por rocas de diversos tamaños, dispuestas con sus caras planas hacia arriba, fue otra de las técnicas constructivas identificadas. Este tipo de ingeniería vial solo fue hallado en dos sectores muy particulares. En uno de ellos se trató de un empedrado de rocas de tamaño mediano dispuestas sobre una superficie friable que coincide con un sector del trazado donde desciende una pequeña quebrada transversal, lo que condujo a pensar en la elaboración de un determinado diseño de infraestructura para controlar el drenaje sobre el camino (Figura 4.b). En el otro caso, se trató de un pequeño segmento de empedrado irregular, conformado por rocas de tamaño mediano y grande, que desciende hacia el río, por lo que creemos que podría tratarse de un mecanismo para controlar los embates del agua en épocas de crecidas.

Otro mecanismo para control del agua consistió en la implementación de drenajes transversales a la vía. Es muy frecuente encontrar este tipo de rasgos en caminos expuestos a las fuertes lluvias de verano, como las que acontecen en esta región. Una particularidad de uno de los canales observados es que las rocas de los lados sobresalían unos centímetros sobre la superficie del camino, lo que no constituía ningún impedimento para la circulación pedestre.

Uno de los segmentos más conspicuos del sector estudiado es el correspondiente al portezuelo o abra de la Cuesta de Zapata (1875 msnm). Presenta un camino de $3 \mathrm{~m}$ de ancho que asciende/desciende en zigzag por la ladera NE, y está conformado por un alto muro de protección que supera el metro de altura (Figura 4.c). Si bien esta modalidad ya fue señalada anteriormente, aquí se destaca por la altura significativa de sus muros, la presencia del abra como límite natural de paso y la alta visibilidad hacia el entorno circundante principalmente en dirección NE, dado que hacia el SO del portezuelo la quebrada se encajona abruptamente debido a su origen tectónico.

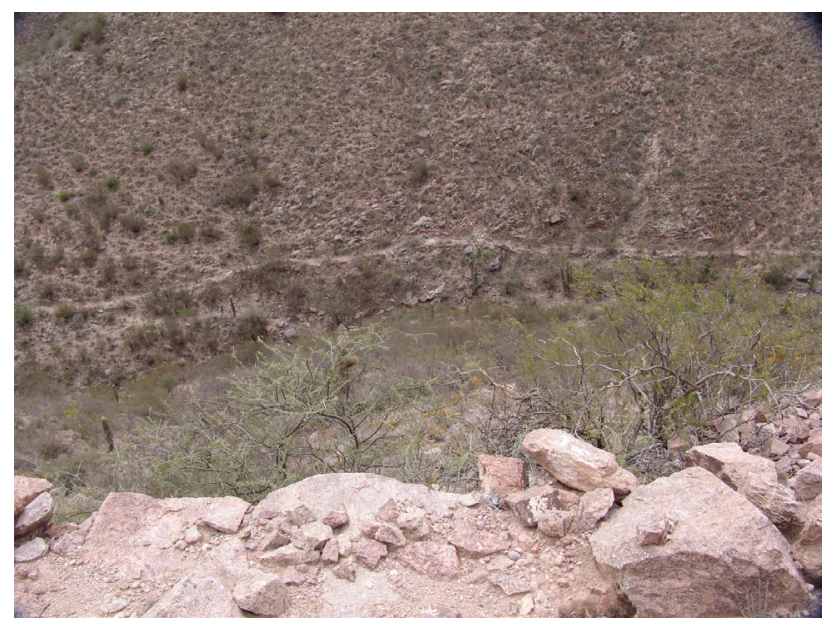

Figura 2. Camino incaico en la Cuesta de Zapata visto desde la actual Ruta Provincial Nº 3.

Figure 2. Inca road on the Zapata Slope seen from the State Route 3.

Durante nuestros primeros trabajos de prospección, el abra de la Cuesta de Zapata constituyó un rasgo geográfico propicio para la búsqueda de una apacheta o altar de piedra, sin llegar a resultados positivos. Es conocido en el mundo andino la importancia de estos lugares amplios entre montañas que permiten el paso de los viajeros con mayor facilidad, actúan como una divisoria de aguas y constituyen verdaderos límites geográficos naturales y culturales. Son espacios ritualizados con un alto contenido simbólico que implican de algún modo un cambio en el paisaje. En estos lugares, los viajeros y caravaneros suelen liberarse de las fatigas del recorrido (colocando rocas, acullicos, sandalias, entre otras cosas) y, también, realizar ofrendas de alcohol y cigarrillos a la Pachamama y deidades tutelares para pedirles protección y tener un
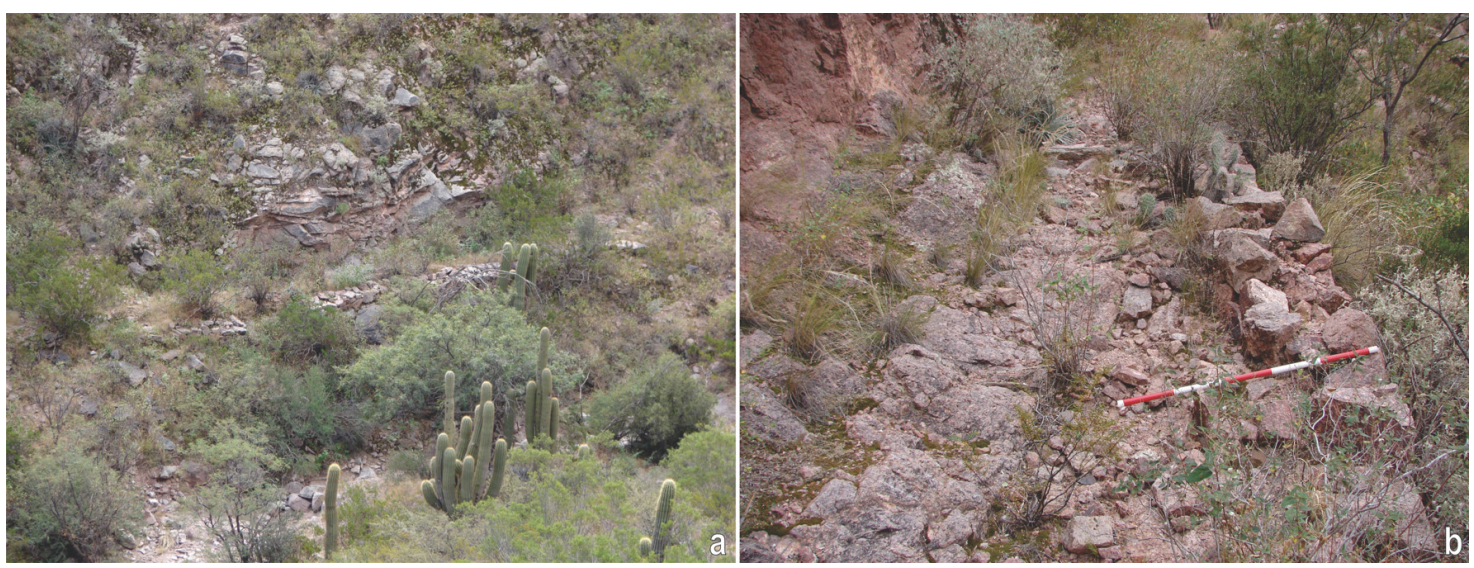

Figura 3. Tipos de rasgos estructurales más recurrentes del camino. Referencias: a) camino con talud y excavación sobre la ladera; b) camino con talud, excavación ladera adentro y muro de protección.

Figura 3. Types of most recurrent structural features of the road. References: a) road with a slope and excavation on the hillside; b) road with a slope, inner excavation of the hillside and protection wall. 
Figura 4. Otros rasgos asociados. Referencias: a) punto de contacto entre el camino incaico y el lecho del río, evadiendo un sector de grandes bloques rocosos; b) camino empedrado (ancho del camino: 3,4 $\mathrm{m})$; c) camino con muro de protección que asciende/desciende del abra o portezuelo de la Cuesta de Zapata; d) pequeño montículo de piedras localizado sobre el borde interno del camino.

Figure 4. Other associated features. References: a) contact point between the Inca road and the river bed, avoiding an area of big stone blocks; b) stone paved road (3-4 $\mathrm{m}$ wide); c) road with protection wall ascending/descending from a pass of the Zapata Slope; d) small stone mound located on the inner edge of the road.

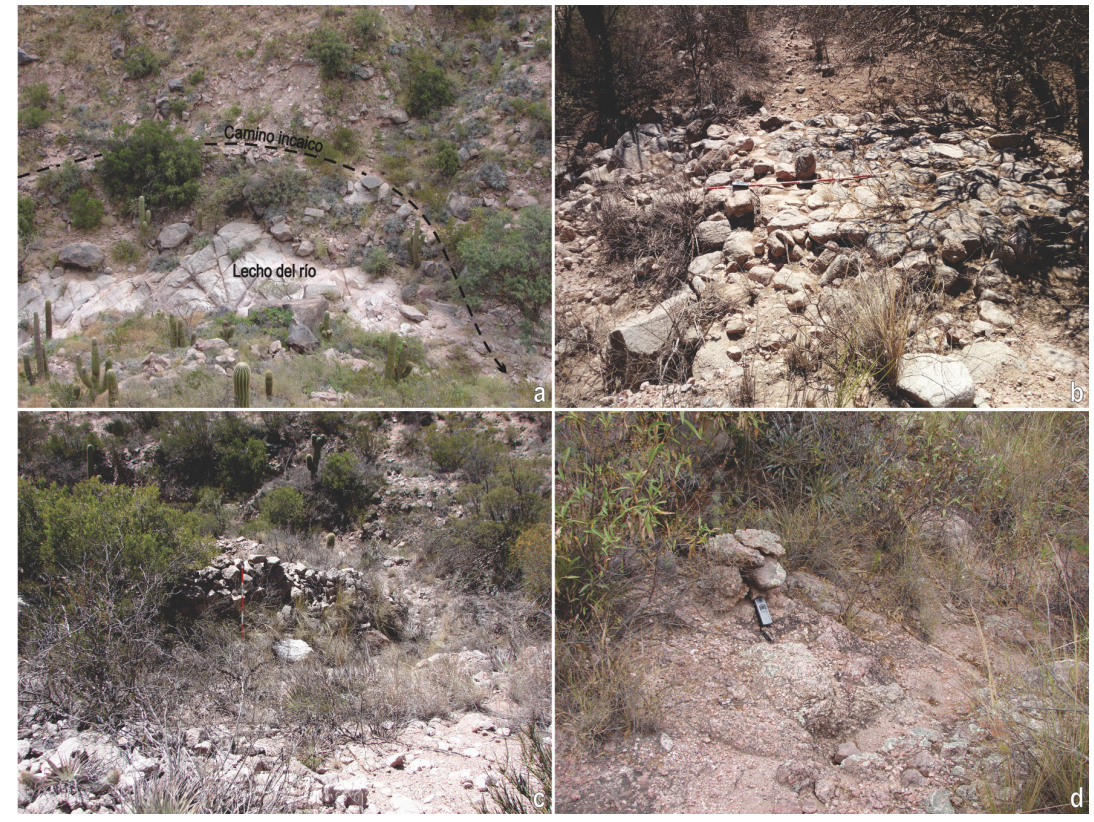

buen viaje (Galdames Rosas, 1990; Nielsen, Angiorama y Ávila, 2017; Núñez, 1976; Pimentel, 2009). En la ruta que estamos describiendo, el abra no solo sirvió para la instalación del camino prehispánico sino también para la instalación de la antigua Ruta Nacional N 40 y de una torre correspondiente al tendido eléctrico de alta tensión entre los departamentos de Belén y Tinogasta. Es decir, este punto de unión de rutas o tendidos de comunicación representa un paso natural emblemático para las sociedades del pasado y del presente. Lamentablemente, es probable que las últimas intervenciones antrópicas mencionadas hayan afectado la conservación de este lugar, al punto de dificultar el hallazgo de un rasgo tan singular como la apacheta.

Rasgos arquitectónicos y mobiliarios asociados al camino de la Cuesta de Zapata

Entre los elementos asociados al camino hemos hallado un pequeño montículo de rocas de 0,46 $\mathrm{m}$ de altura sobre el borde interno del trazado. Por su tamaño, forma y disposición podría tratarse de un mojón para demarcar el camino (Vitry, 2002). En cuanto a su temporalidad, es difícil establecer una cronología ya que su presencia en el camino incaico no asegura que sea contemporáneo al Período Inca (1420-1536 D.C.). Teniendo en cuenta que se trata de una vía que también fue utilizada en tiempos posteriores a los incas, podría tratarse de una acumulación de época Colonial, Republicana o incluso actual (Figura 4.d).

También se halló una estructura con forma de $U$ de 3,10 x 2,20 x 2,20 m localizada sobre una pequeña explanada a la vera del camino. La misma se dispone de espaldas al camino, y abierta hacia una pequeña senda lateral que se desprende de aquel y luego se vuelve a unir. Esta estructura presenta paredes laterales, dobles en la base y simples en la parte superior, construidas con piedras de diversos tamaños sin mortero, que han sido canteadas y seleccionadas. El ancho de las mismas varía de 0,50 a 0,60 $m$. En cuanto a su pared $N$, ésta se apoya sobre la ladera del cerro y tiene un ancho de 0,50 m (Figura 5). Hacia la parte inferior de la pequeña explanada se hallaron una serie de muros alineados que podrían funcionar como muros de contención para permitir el relleno y nivelado de la pendiente. Las condiciones de visibilidad desde esta estructura hacia el paisaje circundante son relativamente bajas. A manera de hipótesis creemos que este conjunto arquitectónico pudo funcionar como un lugar de descanso o refugio (parapeto) para los viajeros y sus animales. Su disposición en relación con la traza principal se diferencia de las estructuras abiertas registradas por Vitry (2000) en el tramo Morohuasi-Incahuasi (departamento de Rosario de Lerma, provincia de Salta, NO argentino). Estas últimas son estructuras directamente adosadas al camino incaico, y que según Vitry (2000) pudieron ser construidas en función del mismo, formando una sola construcción arquitectónica, planeadas y construidas en conjunto. De este modo, y hasta tanto no realizar excavaciones arqueológicas, se utilizará de acuerdo con Nielsen, Berenguer y Sanhueza (2006) la denominación de sitio de enlace para evitar cualquier tipo de connotación funcional y de jerarquía. Lo mismo sucede en cuanto a su carácter cronológico. En las proximidades de este conjunto arquitectónico hemos hallado restos de metales muy oxidados que posiblemente correspondan a latas de conservas. Por esta razón, creemos que esta estructura, independientemente de si corresponde o no a momentos prehispánicos, sin duda alguna ha sido reutilizada en tiempos recientes.

Hacia el SO de la Cuesta de Zapata, una vez que el camino sale del fondo de la quebrada entra en una planicie ondulada generada a partir de los abanicos coalescentes que descienden sobre el piedemonte occidental de la 
sierra de Zapata, en dirección perpendicular al curso principal del río Las Lajas. Sobre dicha superficie el camino adquiere mayor rectitud, en sentido NE-SO, adquiriendo un ancho de 5 a $8 \mathrm{~m}$ con un muro de contención que no supera los 0,60 $\mathrm{m}$ de altura (Figura 6.a). Sobre el borde de este segmento de camino se hallaron asociadas diferentes concentraciones de cerámica entre las que se destacan fragmentos de un cuello de aríbalo/aribaloide correspondiente al estilo Inca Provincial (Figura 6.b). A pocos metros también se encontraron dos conjuntos rocosos graníticos -separados entre sí por una distancia de $65 \mathrm{~m}$ - con un par de oquedades en su superficie (Figura 6.c y d). Si bien no descartamos que estas oquedades pudieran estar vinculadas con espacios sagrados de ofrenda en circuitos de tránsito, por el pulido de su concavidad es probable que fueran utilizadas como unidades de molienda. Al respecto, Sempé (1973, lámina III-11; 1976, p.361) señala la presencia del sitio Km 765764 compuesto por un gran mortero comunal trabajado en roca granítica con sus respectivas manos de moler in situ y cerámica de los períodos Tardío (900/1000-1420 D.C.) e Inca. Este sitio se encuentra a $3 \mathrm{~km}$ en línea recta al SE de los hallados por nosotros, y según la autora se ubica dentro de un campo de siembra. Próximo al mortero múltiple, también menciona los restos de una antigua vivienda de adobes de paredes gruesas y que posiblemente sea de época Colonial por su semejanza con la residencia principal del mayorazgo de Juan Gregorio Bazán de Pedraza (construida entre los años de 1712 y 1714) localizada en Anillaco, departamento de Tinogasta.

Volviendo al último segmento de camino analizado, desde allí se bifurca otra vía hacia el $\mathrm{O}$, perpendicular al río Las Lajas, que conduce hacia una pequeña planicie elevada sobre la margen izquierda (aguas arriba) del río mencionado. En esta planicie hallamos un sitio arqueológico que presenta un conjunto de recintos

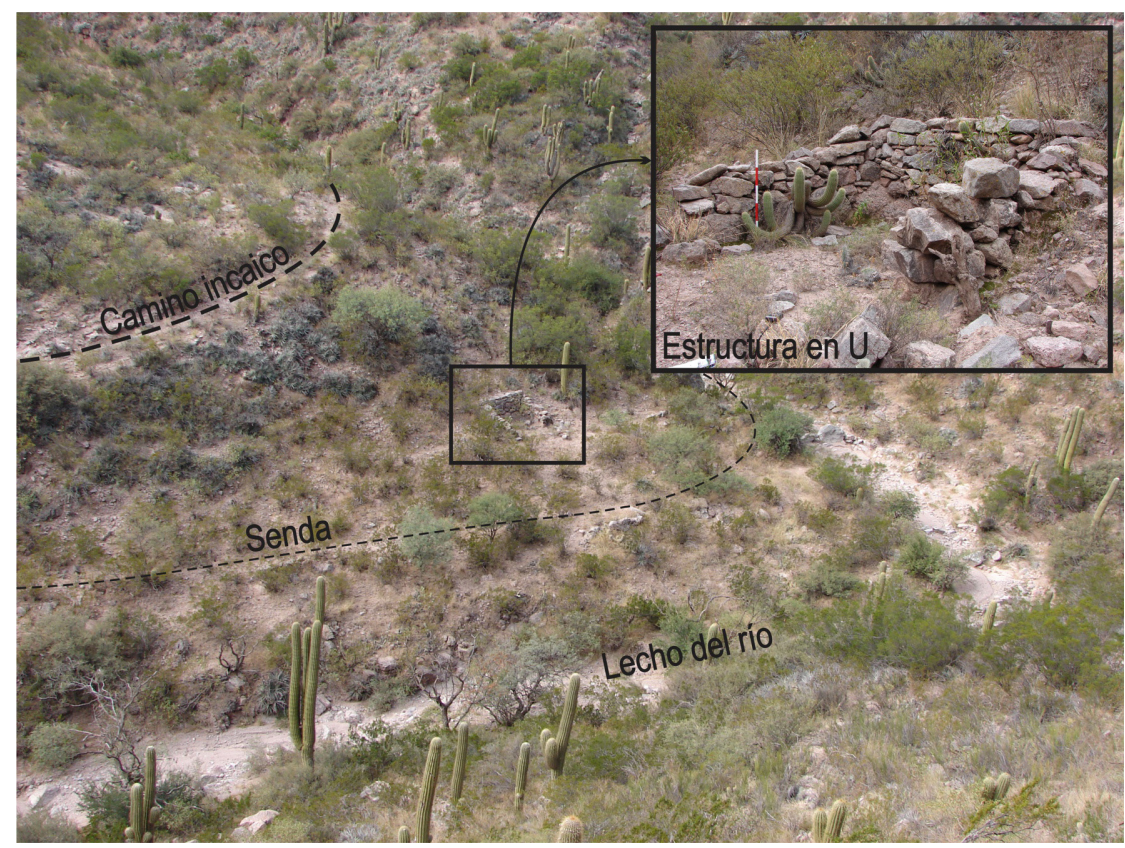

rectangulares y cuadrangulares de diversos tamaños, algunos de los cuales están adosados linealmente entre si formando conjuntos de dos y hasta cuatro recintos. Estos recintos se disponen de manera circular delimitando un amplio espacio interior a modo de plaza. Los mismos han sido construidos con muros dobles, algunos alcanzan un metro de ancho, de piedras redondeadas seleccionadas y ensambladas entre sí, conformando lo que se conoce como un aparejo rústico de forma natural (Calvo, 1987). Este tipo de arquitectura es semejante a la existente en los sitios Costa de Reyes (Catamarca), Tambería del Inca (La Rioja) y Hualfín-Inka (Catamarca). Hacia el O del sitio se detectaron restos de lo que podría ser un muro perimetral con un vano de acceso hacia el gran espacio interior. En cuanto a la cerámica en superficie, se observó alfarería correspondiente a los estilos Belén, Inca Provincial y utilitaria. También se detectaron diferentes pozos de huaqueo en algunos recintos.

Las evidencias arquitectónicas y ergológicas en superficie y el estudio del paisaje nos conducen a pensar que se trataría de un sitio de enlace, a modo de tampu, dentro de la ruta que conecta El Shincal de Quimivil y Watungasta. Investigaciones recientes le han atribuido la denominación de Río del Inca-Lucke (Ratto y Orgaz, 2019). ${ }^{1}$ Estratégicamente se ubicó en un lugar que puede ser fácilmente alcanzado desde El Shincal de Quimivil por la ruta de la sierra de Zapata, como también desde el enclave agrícola de Los Colorados (asociado a El Shincal) por una supuesta ruta que transita por el piedemonte oriental del cerro Fraile y el Paraje El Durazno

\footnotetext{
${ }^{1}$ La denominación de este sitio constituye una incógnita. El sitio fue descubierto por César L. A. Carrizo (habitante de Belén) y quien suscribe este artículo en septiembre de 2017. Inmediatamente se comunicó el hallazgo y sus coordenadas geográficas a la Dirección Provincial de Antropología de Catamarca y a la Dra. Norma Ratto, por localizarse en su zona de estudio. Según una carta geológico-económica del Servicio Geológico Minero Argentino (SEGEMAR), Hoja 13c, Fiambalá, escala 1:200.000 (González Bonorino, 1972) el sector del hallazgo recibe el nombre de Zapata. Este topónimo coincide con las menciones que nos han realizado algunos pobladores de El Durazno de Tinogasta (paraje localizado a pocos kilómetros del sitio) durante unas entrevistas realizadas en abril de 2019. Por otro lado, según nuestro análisis de los artículos de Uhle (1912) y Ratto (2015) propusimos la hipótesis de que podría tratarse del Río del Inca excavado por Max Uhle en 1893. Según Ratto y Orgaz (2019) no se trataría del Río del Inca de Uhle, sino de un sitio diferente que han decidido denominar Río del Inca-Lucke.
}

Figura 5. Estructura abierta en U hallada a la vera del camino.

Figure 5. U-shaped open structure found at the roadside. 


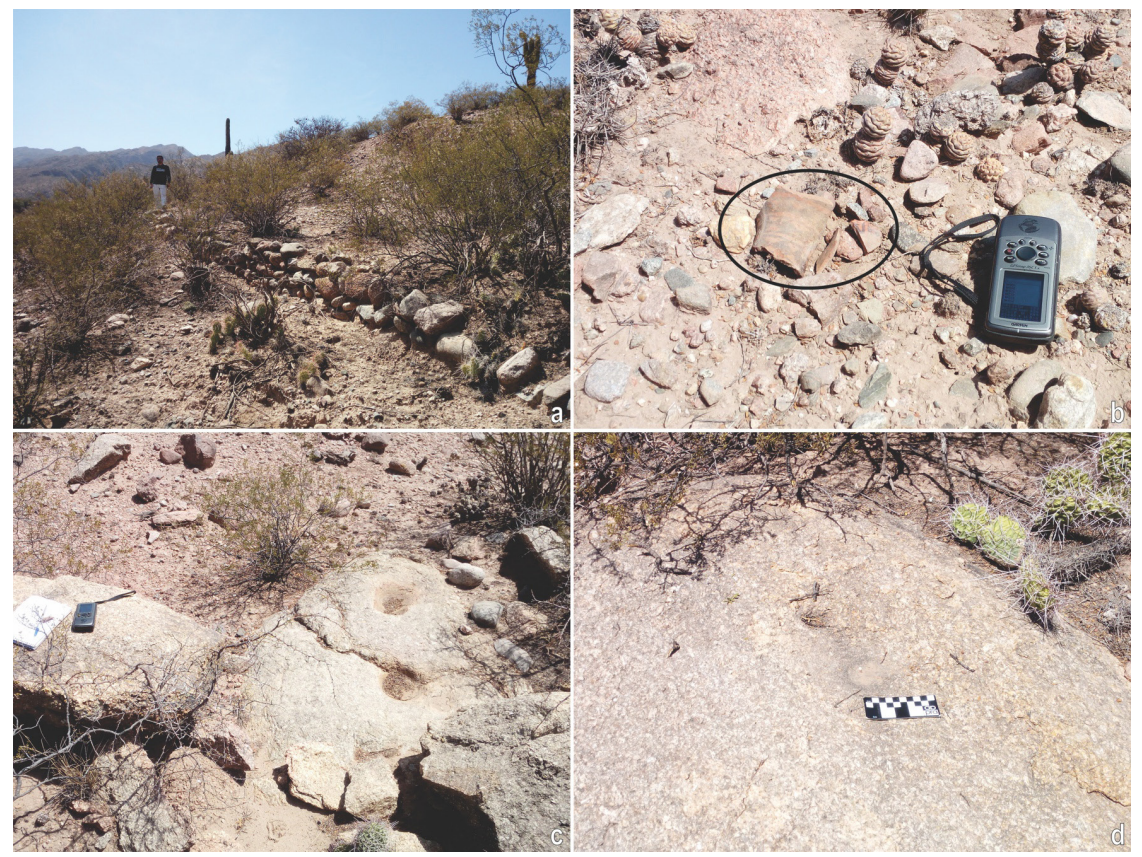

Figura 6. Hallazgos al SO de la Cuesta de Zapata: Referencias: a) camino con talud sobre la planicie ondulada (ancho del camino: $5 \mathrm{~m}$ ); b) cerámica Inca Provincial hallada al borde del camino incaico; c y d) conjuntos de morteros múltiples próximos a la vera del camino.

Figure 6. Findings on the southwest of the Zapata Slope. References: a) road with a slope on the undulated plain (road width $5 \mathrm{~m}$ ); b) Inca Provincial pottery on the edge of the Inca road; c) and d) multiple mortar sets on the edge of the road.

de Tinogasta. Esta última hipótesis ya fue formulada con anterioridad mientras realizábamos el estudio micro y macromorfológico del tramo El Shincal de Quimivil - Los Colorados - La Ramadita (Moralejo, 2011).

Desde este sitio de enlace la ruta se dirige hacia el SO hasta alcanzar la quebrada Abra del Paraguay, donde se localiza el chaskiwasi de Anillaco a una distancia aproximada de 19,5 km. Una vez en el abra respectiva, se puede entrar en contacto visual con la quebrada de La Troya donde yace el centro político, administrativo y ceremonial de Watungasta (Raffino et al., 2008). Aún faltan estudios más profundos del camino en este último tramo, razón por la cual nuestro aporte para el sector de la Cuesta de Zapata significa la formulación de nuevas preguntas y, por ende, la apertura de nuevas vías de investigación acerca de un sector poco explorado del centro-oeste catamarqueño.

\section{Discusión}

El segmento de camino aquí presentado tiene una longitud de 5,27 km y corresponde al sector conocido como la Cuesta de Zapata, perteneciente a la porción $S$ de la sierra de Zapata. Los datos provenientes de su análisis micromorfológico revelan una relativa variabilidad e inversión infraestructural, que se refleja tanto en sus diferentes aspectos espaciales y formales (variación del ancho según la topografía, excavación sobre la ladera, relleno y nivelación de la traza, presencia de taludes y muros de protección, cortes abruptos artificiales sobre la roca de la ladera, diseños de ascenso y descenso en zigzag, elección deliberada de los puntos de vadeo del río, empedrado, implementación de drenajes transversales) como en los elementos asociados del paisaje (mojón, estructura con forma de U, alfarería, unidades de molienda, presencia de un sitio de enlace llamado Río del Inca-Lucke). que lo circularon y se apropiaron del la circulación a lo largo del tiempo y a través del espacio geográfico (Berenguer y Pimentel, 2017).

Particularmente, este segmento de la Cuesta de Zapata significa la continuación hacia el SO del camino trazado entre El Shincal y el tampu Tambillo Nuevo -que ya hemos analizado en otro trabajo (Moralejo, 2017)-, por lo que constituye un aporte más al estudio de la vialidad regional. Es decir, el camino de la cuesta formó parte de un circuito mayor que atravesaba la sierra de Zapata para conectar - de NE a SO- dos centros nodales como El Shincal de Quimivil y Watungasta. Desde El Shincal se podía alcanzar en dirección NE otros nodos camineros como Hualfín-Inka ( $\mathrm{N}$ del valle de Hualfín) y Punta de Balasto (S del valle de Yocavil o Santa María) para luego continuar hacia el valle Calchaquí y seguir con rumbo norte (Raffino, 1991; Tarragó, Marchegiani, Palamarczuk y Reynoso, 2017). Desde Watungasta, se podía seguir hacia el $\mathrm{O}$ a través del paso cordillerano de Comecaballos hasta alcanzar el valle chileno de Copiapó; hacia el N en dirección a la puna catamarqueña y hacia el $\mathrm{S}$-por el sitio Costa de Reyes- en dirección a la sierra de Famatina ( $N$ de la provincia de La Rioja), para luego continuar hacia los territorios más australes del Kollasuyu (Martín, 2015; Orgaz y Ratto, 2013; Raffino, 1995; Raffino, Moralejo y Gobbo, 2010; Vitry, 2007).

Volviendo a lo que sucede en el interior de la sierra de Zapata. Se destaca la asociación con dos sitios de enlace a manera de tampus sumamente importantes: uno de ellos el sitio Tambillo Nuevo (Moralejo, 2009, 2011) localizado hacia ambos lados del río El Tambillo en el sector central de la sierra de Zapata; y el otro Río del Inca-Lucke, localizado hacia la margen izquierda (aguas arriba) del río Las Lajas próximo a la cabecera SO de la Cuesta de Zapata. Entre ambos puntos de enlace media 
una distancia de 15,5 km, equivalente a media jornada de marcha. Por las características arquitectónicas, patrón de asentamiento y los estilos alfareros observados, ambos sitios permiten establecer una cronología relativa de esta ruta para el momento de ocupación incaica del NOA.

En el caso particular del Tambillo Nuevo, las investigaciones revelan la presencia de alfarería Inca Provincial con una alta predominancia de aríbalos/aribaloides. A esto se suman otros componentes como kanchas (o recintos perimetrales compuestos), una plataforma ceremonial y un tramo de camino incaico, entre otros (Moralejo, 2009, 2011). Para este sitio también contamos con una datación de $460 \pm$ 50 AP (LP-2152, d14C, carbón vegetal) (Moralejo, 2011). Todo ello permite sostener que en este lugar se habrían realizado diversas actividades como el alojamiento de personas, control vial y reaprovisionamiento de caravanas en tránsito, en un contexto donde las prácticas rituales tuvieron un papel fundamental para el sostenimiento de las políticas implementadas por el Estado Inca.

Con respecto a la evidencia analizada dentro del segmento de la Cuesta de Zapata, la infraestructura vial está debidamente desarrollada y su técnica constructiva refleja claramente la intervención incaica, típica de zonas montañosas con quebradas profundas. Asimismo, la continuación con el tramo El Shincal de Quimivil - Tambillo Nuevo, la instalación asociada Río del Inca-Lucke y la existencia de cerámica Inca Provincial correspondientes a vasijas para traslado de líquidos (sugerentemente hallada al costado del camino), permiten corroborar la filiación incaica del camino. Vale destacar, como mencionaremos más adelante, que esta filiación se refiere al uso y reacondicionamiento formal de la ruta. En cuanto a la estructura en U como bien se indicó más arriba, será importante realizar excavaciones para determinar su cronología absoluta y comprender su funcionalidad asociada a la traza caminera.

El ancho del camino también es un tema interesante para destacar. Las condiciones naturales y topográficas de la quebrada -como pendientes empinadas y angostura- fueron las responsables de que esta vía tuviera una construcción formal y se mantuviera entre 2 y 4,5 m dentro de la quebrada, es decir un ancho mínimo para que resultara transitable. Ello sin duda pudo haber condicionado la manera en cómo se realizaba y organizaba el movimiento. Por ejemplo, en el caso de las caravanas de llamas que circulaban por los caminos, era importante la comunicación a través de sonidos emitidos por determinadas llamas para advertir al resto en el momento de entrar en una quebrada angosta, y así evitar cualquier tipo de aglomeración y despeñamiento. En una entrevista realizada a un arriero de llamas de Tambobamba (departamento de Apurímac, S del Perú), éste manifestaba lo siguiente:

...cada 12 animales una llevaba un cencerro en el cuello, la primera de adelante sonaba talan talan que era "perderganar", el segundo cencerro estaba a la mitad de la recua, sonaba canracmi ("hay todavía"), esto era pasado 12 animales o 24 animales, y la campanilla al final de la recua sonaba chilin chilin (chayllanan chayllanan), "ya no hay, eso nomas". Era muy importante porque cuando se encontraban dos recuas en una quebrada de paso angosto podían las llamas empujarse y caer al precipicio. (Augusto Cardona R., comunicación personal, 2018).

Este relato etnográfico podría corroborarse con la alta frecuencia de muros de protección observados a lo largo del camino estudiado.

Volviendo al tema de la cronología de esta ruta de movilidad, las investigaciones previas indican que su uso se puede extender hasta por lo menos el Período Temprano (ca. 500 A.C.-400 D.C.). Esto se sostiene a partir del hallazgo de pucos o escudillas estilo Ciénaga y restos de vasijas globulares estilo Aguada (gris, pintada y allpatauca) en las adyacencias del Tambillo Nuevo y en otro sitio, denominado Corralito, dentro de esta ruta (Moralejo, 2011, 2017). Esta idea también se puede corroborar con la presencia de un sitio, denominado $\mathrm{Km}$ 761, registrado al S de la Cuesta de Zapata por González y Sempé (1975) y donde se hallaron estructuras de piedra de planta circular y cuadrangular; morteros, conanas y manos; lascas de obsidiana y fragmentos de tubos de pipa junto a cerámica del Período Temprano (estilos Saujil, Ciénaga) y Medio (estilo Aguada) (ca. 400-950 D.C.). En cuanto a las características de la ruta, se trataba de una vía informal con anchos variables y un trazado irregular en el paisaje, generada por el desgaste a raíz del continuo movimiento de personas y animales (Moralejo, 2011).

Posteriormente, cuando los incas ocupan la región, entre comienzos del siglo XV y principios del XVI, se produce una reformulación política e ideológica de esta ruta con sus consecuentes cambios estructurales. De este modo, instalaron dos centros nodales como El Shincal de Quimivil y Watungasta y sitios de enlace como Tambillo Nuevo y Río del Inca-Lucke, junto a un sistema vial formalmente construido que le permitieron intensificar sistemáticamente el tráfico y la comunicación interregional. Al mismo tiempo, este paisaje vial estaba acompañado de diversos elementos sagrados de la cosmovisión andina como grandes rocas tokankas, ojos de agua y rocas waka en el tramo El Shincal de Quimivil - Tambillo Nuevo (Moralejo y Aventín Moretti, 2015; Moralejo, 2017), y pasos naturales que marcaban cambios importantes en la velocidad, visibilidad y ambiente de un camino como el caso del portezuelo o abra de la cuesta mencionado en este artículo. Es decir, todos estos rasgos modelaban y representaban un sistema vial con alto contenido simbólico y una gran capacidad de agencia que le permitía actuar y generar comportamientos sobre los caminantes.

Ahora, si comparamos esta ruta con las investigaciones 
que venimos realizando hace varios años en otro trayecto, El Shincal de Quimivil - Pozo de Piedra, se pueden advertir diferencias en cómo y para qué fueron concebidas. Por un lado, se encuentra lo que podríamos considerar una ruta longitudinal por Zapata que permitía regular el movimiento de personas y animales de carga, la articulación y la circulación de bienes con los valles vecinos del $\mathrm{S}$ e incluso con el $\mathrm{N}$ de Chile, la puna catamarqueña y la parte más meridional del NOA; y por otro, una ruta transversal hacia el NO que permitía alcanzar los productos agrícolas de Los Colorados y Las Vallas, para luego ser depositados, utilizados y redistribuidos en El Shincal a través de diferentes mecanismos de hospitalidad ceremonial (Giovannetti, 2015; Moralejo, 2011; Moralejo y Couso, 2012). Esta diferencia en las modalidades del tráfico indica que existía una racionalidad espacial reproducida para cada camino y que podría estar relacionada con los contenidos que las comunidades otorgaban a los espacios físicos a través de sus actividades diarias, creencias y sistemas de valores (Anschuetz, Wilshusen y Scheick, 2001; González Godoy, 2017). En este sentido, los caminos como espacios de tránsito, percepción, experimentación e interacción con otros individuos y el medio, se convierten en paisajes construidos con determinadas pautas de organización o regularidad. Desde una perspectiva de la arqueología internodal, estas modalidades del tráfico podrían responder a diferentes estrategias de movilidad basadas tanto en el tráfico especializado como en el tráfico incorporado (Nielsen, 2006). Podríamos decir que durante el momento incaico las interacciones sociales a través de la sierra de Zapata se habrían dado -principalmente- en el marco de una estrategia de tráfico especializado focalizada en el tránsito (desplazamiento de bienes, personas y animales de carga de una región a otra). Mientras que las interacciones hacia el NO de El Shincal (ruta El Shincal de Quimivil - Pozo de Piedra) se habrían mantenido bajo una modalidad de tráfico incorporado donde predominaban prácticas de tipo extractiva o de apropiación de recursos vegetales como así también de pastoreo. Por otra parte, si bien nos hemos referido a modalidades de circulación coexistentes durante el momento Inca, sus orígenes podrían remontarse al Período Temprano mediante circuitos de desplazamiento estacional organizados en función de la caza y la recolección (Nielsen, 2006).

Este camino continuó en uso y siendo resignificado durante la época Colonial y Republicana. Hacia 1536 tenemos el paso del ejército de Diego de Almagro en lo que fue la primera expedición española al NOA y Chile (Raffino, 1995, 2004; Strube Erdmann, 1958; Vitry, 2007). Ratto y Boixadós (2012), de acuerdo a un padrón de 1627 señalan que los españoles residentes en San Juan Bautista de la Rivera (una de las cinco fundaciones de la antigua Londres) ingresaron al valle de Fiambalá a través de la Cuesta de Zapata.

Montes (1959), por su parte, cuando se refiere al segundo alzamiento Diaguita o "Gran Alzamiento" (1630-1643), relata la persecución que hizo en 1635 el ejército del Maestre de Campo Pedro Ramírez de Contreras y el Capitán Juan Núñez Dávila sobre las tropas de malfines y abaucanes lideradas por el cacique Juan Chalimin. Los españoles que estaban asentados en Batungasta (Watungasta) tuvieron que moverse por la sierra de Zapata, hacia el $\mathrm{N}$ de la antigua jurisdicción de Londres, en busca del pueblo de los malfines. ${ }^{2}$ Esto señala que hacia la primera mitad del siglo XVII, donde había fuertes conflictos entre aborígenes y españoles, existía un tránsito fluido y permanente por Zapata con la intención de conectar diferentes territorios de la jurisdicción de Londres (Gobernación del Tucumán) localizados al S y N de la Cuesta de Zapata.

Entrado el siglo XVIII y ya controladas las rebeliones aborígenes y consumadas diferentes encomiendas, se registra el viaje que tuvo que emprender en 1712 el Maestre de Campo del mayorazgo de Anillaco (valle de Fiambalá) Juan Gregorio Bazán de Pedraza hacia Paraguay, a través de la quebrada Abra del Paraguay y la sierra de Zapata, para hacerse cargo de la gobernación de dicho territorio (Brizuela del Moral, 2003; Raffino et al., 2008).

Esta movilidad se mantuvo por este antiguo camino hasta la segunda mitad del siglo XIX, cuando comienza a construirse, sobre una cota más elevada, una traza para tropas y vehículos de mayor porte, la cual posteriormente condujo a la creación de la Ruta Nacional $N^{\circ} 40 .{ }^{3}$ Por esta razón, en gran parte del recorrido por la sierra de Zapata, la antigua traza del camino incaico sirvió de base para pensar, trazar y construir dicha ruta nacional y favorecer la comunicación entre las provincias de Catamarca y La Rioja. Al respecto, la Dirección Nacional de Vialidad (DNV, 1936, p.81-82) manifestaba la importancia desde el punto de vista práctico que tenía el camino de los incas para los objetivos de construcción caminera que perseguía el Estado Nacional. Tal es así que se contrató al Dr. Francisco de Aparicio del Museo Antropológico y Etnográfico de la Facultad de Filosofía y Letras de la Universidad de Buenos

\footnotetext{
2 El pueblo de los malfines correspondería a la localidad de Hualfín, localizada en el extremo $\mathrm{N}$ del valle homónimo, en tiempos históricos (Wynveldt, Ferrari y López, 2017).

${ }^{3}$ En el año 1869 se firma un contrato entre el Gobierno de la Provincia de Catamarca (con autorización del Gobierno Nacional) y el Sr. Enoc Espeche para construir el paso por la Cuesta de Zapata y la quebrada del mismo nombre. Las obras consistían en abrir y rectificar el camino de 18 leguas que conduce del Distrito de Londres (Departamento de Belén) hasta el pueblo de Tinogasta (Departamento de Tinogasta), dándole un ancho de doce varas (lo que equivale aproximadamente a $10 \mathrm{~m}$ ) y rectitud siempre que fuera posible. En el caso particular de la cuesta y quebrada de Zapata, el camino debía hacerse en la cuesta tratando de lograr el mayor ancho posible para que las tropas cargadas pudieran transitar cómodamente, inclusive si se encontraban al mismo tiempo una frente a la otra. También se acordó preparar sobre la Cuesta de Zapata algunos espacios de descanso para las tropas o pasajeros que quisieran detenerse (Archivo Histórico de Catamarca [AHC], SG.1, c.39, e.46, f.e, 1869-1871). Esta obra llevada a cabo por Enoc Espeche se convirtió hacia mediados del siglo XX en la Ruta Nacional $N^{\circ} 40$
} 
Aires con el propósito de establecer el recorrido y las características del camino incaico en territorio argentino. De esta manera la DNV podía contar con información científica fehaciente para llevar adelante sus proyectos políticos de ingeniería vial.

En la actualidad, toda la circulación pedestre, con animales y en vehículos (principalmente pequeños y de alta potencia) se realiza exclusivamente por la traza de la antigua Ruta Nacional $\mathrm{N}^{\circ} 40$, que desde hace unas décadas pasó a llamarse Ruta Provincial $N^{\circ} 3$. Por otra parte, la traza del Camino del Inca yace intacta en el fondo de la quebrada, elevada unos metros por encima del lecho del río. Todo ello ha provocado que éste se mantenga cubierto de vegetación y en muy buen estado de conservación.

\section{Conclusiones}

En este artículo hemos presentado un análisis micro y macromorfológico del camino incaico en la Cuesta de Zapata que hasta el momento solo había sido abordado de manera superficial. Estos análisis son producto de recientes investigaciones que además de ampliar la información acerca del segmento vial, constituyen un nuevo aporte para un conocimiento más acabado en el área de estudio durante el Período Inca.

Esta vía representa un segmento de la ruta que permitió el tránsito entre el valle de Hualfín y el campo de BelénAndalgalá (centro de Catamarca) y los valles de Las Lajas y Abaucán (O de Catamarca); y muestra un conjunto de rasgos que responden a una infraestructura relacionada directamente con las prácticas de movilidad y logística del tráfico, en un rango temporal que va desde al menos el Período Temprano hasta la segunda mitad del siglo XIX (cuando comienza a construirse la traza de lo que posteriormente sería la prestigiosa Ruta Nacional N40).

Dentro de la red vial, los resultados obtenidos otorgan una mayor significación espacial y cultural a sitios como El Shincal de Quimivil, Tambillo Nuevo y Watungasta, ya que permiten conocer más sobre aquellos espacios donde ocurría la circulación, y preguntarnos acerca de quiénes viajaban y por qué razones. Por otro lado, sirve de base para generar nuevas y futuras investigaciones vinculadas con la articulación regional y el dominio Inca en el área. Una de ellas se relaciona con el hallazgo del sitio Río del Inca-Lucke, el cual permite retomar y ampliar una antigua hipótesis de trabajo (Moralejo, 2011) acerca de una ruta que podría conectar el enclave agrícola de Los Colorados con el sitio mencionado a través del piedemonte oriental del cerro Fraile, Paraje El Durazno y el valle del río Las Lajas.

Este estudio nos permite resaltar que la construcción del camino de la Cuesta de Zapata estaba relacionada con una modalidad de tráfico especializado que buscó adaptarse a un entorno abrupto de montaña, mediante la construcción de taludes, muros de protección, excavaciones en la ladera, relleno y nivelación, aprovechamiento de los cortes naturales de la roca, empedrados, amojonamiento y selección de los vados del río. Por otro lado, fue necesario instalar un punto de enlace (sitio Río del IncaLucke) próximo a la cabecera SO de la cuesta, en un entorno propicio para el control y abastecimiento del tráfico. Asimismo, este tramo se relacionaba con aspectos simbólicos del paisaje como la circulación a través del abra o portezuelo, como uno de los puntos geográficos de mayor visibilidad, que implicaba el acceso -viniendo desde el NE- hacia el sector más encajonado de la sierra. Esta materialidad no solo reflejaba una fuerte intervención de trabajo sobre una topografía extremadamente compleja y un conocimiento profundo del paisaje, sino también la importancia de esta vía para la interacción interregional. Tanto su infraestructura como su entorno montañoso debieron alterar la percepción de los caminantes al punto de provocar un gran efecto en la construcción y mantenimiento de la memoria colectiva.

La ruta por Zapata posee una larga historia en el tiempo y ha sido continuamente resignificada a lo largo del mismo. Su importancia como uno de los principales ejes longitudinales de comunicación, circulación de bienes y articulación regional permitía también el acceso a los valles meridionales del NOA, razón por la cual creemos importante que se continúe con el estudio de su derrotero $S$ siguiendo un enfoque micro y macromorfológico que permita ahondar tanto en sus aspectos particulares como holísticos.

Quenumá, 16 de Septiembre 2019

\section{Agradecimientos}

A César L. A. Carrizo, Juan Ramón Tiki Reynoso y Darío Iturriza por su apoyo incondicional en nuestras tareas de campo. A la comunidad de Londres y Belén de Catamarca. A nuestro Equipo Interdisciplinario de Investigación El Shincal de Quimivil (ElI-ESQ) de la División Arqueología del Museo de La Plata. A Diego Gobbo por su colaboración en el tratamiento de las imágenes. A nuestro querido Maestro y amigo Rodolfo A. Raffino. A la Municipalidad de Londres, Museo de Sitio El Shincal y Dirección Provincial de Antropología de Catamarca. Al CONICET y UNLP por el financiamiento de las investigaciones. Al Equipo Editorial de la Revista del Museo de Antropología y a los/as evaluadores/as por sus comentarios y sugerencias que permitieron mejorar el artículo.

\section{Bibliografía}

Anschuetz, K. F., Wilshusen, R. H., y Scheick, C. L. (2001). An Archaeology of Landscapes: Perspectives and Directions. Journal of Archaeological Research, 9(2), 157211. doi: dx.doi.org/10.1023/A:1016621326415 
Archivo Histórico de Catamarca. (1869-1871). Cuesta de Zapata. Propuesta, Contrato e Informe sobre la apertura del camino público en la expresada localidad hasta Tinogasta (Sección Gobierno 1, carpeta 39, E. 46, años 1862-1875, foja e). San Fernando del Valle de Catamarca, Argentina.

Berenguer, J. (2004). Caravanas, Interacción y Cambio en el Desierto de Atacama. Santiago de Chile: Sirawi Ediciones.

Berenguer, J., Cáceres, I., Sanhueza, C., y Hernández, P. (2005). El Qhapaqñan en el Alto Loa, norte de Chile: Un estudio micro y macromorfológico. Estudios Atacameños, (29), 7-39. doi: dx.doi.org/10.4067/ S0718-10432005000100002

Berenguer, J., y Pimentel, G. (2010). Arqueología de los "espacios vacíos": una aproximación internodal a las relaciones intersocietales. En Actas del XVII Congreso Nacional de Arqueología Chilena (tomo 2, pp. 13051308). Valdivia, Chile: Ediciones Kultrun.

Berenguer, J., y Pimentel, G. (2017). Introducción al estudio de los espacios internodales y su aporte a la historia, naturaleza y dinámica de las ocupaciones Humanas en zonas áridas. Estudios Atacameños, (56), 3-11. doi: dx.doi.org/10.4067/S0718-10432017000300001

Brizuela del Moral, F. (2003). Historia de las Mercedes de tierra en Catamarca. Siglos XVI al XIX. San Fernando del Valle de Catamarca, Argentina: Cenedit Centro Editor.

Calvo, A. (1987). Estudios acerca de la construcción, arquitectura, y planeamiento inca. Lima, Perú: Ediciones de la Cámara Peruana de la Construcción.

Criado Boado, F. (1999). Del Terreno al Espacio: Planteamientos y Perspectivas para la Arqueología del Paisaje. CAPA. Criterios y Convenciones en Arqueología del Paisaje, 6, 1-82. Recuperado de https://digital.csic.es/handle/10261/5698

Dirección Nacional de Vialidad. (1936). Memoria. Ciudad Autónoma de Buenos Aires, Argentina: Biblioteca Dirección Nacional de Vialidad.

Earls, J. (1979). Astronomía y ecología: la sincronización alimenticia del maíz. Allpanchis Phuturinga, (14), 117-135.

Farrington, I. (1999). El Shincal: un Cusco del Kollasuyu. En C. Diez Marín (Ed.), Actas del XII Congreso Nacional de Arqueología Argentina (tomo 1, pp. 53-62). La Plata, Argentina: Editorial de la Universidad Nacional de La Plata.

Galdames Rosas, L. (1990). Apacheta: la ofrenda de piedra. Diálogo Andino, (9), 10-25.

Giovannetti, M. A. (2015). Agricultura, regadío y molienda en una capital Inkaica. Los sitios El Shincal y Los Colorados, Noroeste Argentino. Oxford, Reino Unido: BAR International Serie 2702.

González, A. R. (1966). Las ruinas del Shincal. En Actas del I Congreso de Historia de Catamarca (tomo 3, pp. 15-28). San Fernando del Valle de Catamarca, Argentina: Junta de Estudios Históricos de Catamarca.

González, A. R., y Sempé, M. C. (1975). Prospección arqueológica en el Valle de Abaucán. Revista del Instituto de Antropología, 2, 49-129.

González Bonorino, F. (1972). Boletín No 127. Descripción geológica de la Hoja 13c, Fiambalá. Ciudad Autónoma de Buenos Aires, Argentina: Dirección Nacional de Geología y Minería.

González Godoy, C. (2017). Arqueología vial del Qhapaq Ñan en Sudamérica: análisis teórico, conceptos y definiciones. Boletín del Museo Chileno de Arte Precolombino, 22(1), 15-34. doi: dx.doi.org/10.4067/ s0718-68942017005000102

Hyslop, J. (1984). The Inka Road System. New York, EE.UU.: Academic Press, Inc.

Latour, B. (2008). Reensamblar lo social: una introducción a la teoría del actor-red. Ciudad Autónoma de Buenos Aires, Argentina: Ediciones Manantial.

Martel, A., Zamora, D., y Lépori, M. (2017). Tráfico y movilidad caravanera en la puna catamarqueña: una mirada internodal. Estudios Atacameños, (56), 197-223. doi: dx.doi.org/10.4067/S0718-10432017005000004

Martín, S. (2015). Caminos dobles del Kollasuyu: dualidad y peregrinajes en el Qhapaq Ñan de la sierra de Famatina (La Rioja-Argentina). Revista de Antropología del Museo de Entre Ríos, 1(1), 44-54. Recuperado de http://ppct. caicyt.gov.ar/index.php/antropmuser/article/view/6517

Montes, A. (1959). El Gran Alzamiento Diaguita. Revista del Instituto de Antropología, 1, 81-159.

Moralejo, R. A. (2009). El "Tambillo Nuevo" de la Sierra de Zapata (provincia de Catamarca). Arqueología, 15, 207-215. Recuperado de http://revistascientificas.filo.uba. ar/index.php/Arqueologia/article/view/1705

Moralejo, R. A. (2011). Los Inkas al sur del Valle de Hualfín: organización del espacio desde una perspectiva paisajística (tesis de Doctorado $N^{\circ} 1150$ ). Facultad de Ciencias Naturales y Museo, Universidad Nacional de La Plata, La Plata, Argentina. Recuperado de http://sedici. unlp.edu.ar/handle/10915/5242

Moralejo, R. A. (2017). Arqueología y paisaje en el interfluvio 
de Zapata, Catamarca, Noroeste Argentino. Boletín del Museo Chileno de Arte Precolombino, 22(1), 119-136. doi: dx.doi.org/10.4067/S0718-68942017005000203

Moralejo, R. A. (2018). Análisis micromorfológico de un tramo de Camino Inka en la Cuesta de Zapata (Catamarca, Noroeste argentino). Arqueología Iberoamericana, S2, 3-8. Recuperado de http://www.laiesken.net/arqueologia/ archivo/2018/S201

Moralejo, R. A., y Couso, M. G. (2012). La organización regional incaica en el Valle de Hualfín (provincia de Catamarca, Argentina): El Shincal de Quimivil y la red vial vinculante. En J. F. Buján (Ed.), Ciudades y Territorio en América del Sur, siglos XV y XVI (pp. 77-112). Ciudad Autónoma de Buenos Aires, Argentina: Ed. Nobuko.

Moralejo, R. A., y Aventín Moretti, M. (2015). Los estudios de vialidad en El Shincal de Quimivil. En R. A. Raffino, L. A. lácona, R. A. Moralejo, J. D. Gobbo y María G. Couso (Eds.), Una capital Inka al sur del Kollasuyu: El Shincal de Quimivil (pp. 105-125). Ciudad Autónoma de Buenos Aires, Argentina: Fundación Azara.

Morláns, M. C. (1995). Regiones naturales de Catamarca. Provincias geológicas y provincias fitogeográficas. Revista de Ciencia y Técnica, 2(2,1), 1-41.

Nielsen, A. E. (2006). Estudios internodales e interacción interregional en los Andes Circumpuneños: teoría, método y ejemplos de aplicación. En H. Lechtman (Ed.), Esferas de interacción prehistóricas y fronteras nacionales modernas: los Andes sur centrales (pp. 29-62). Lima, Perú: Instituto de Estudios Peruanos, Institute of Andean Research.

Nielsen, A. E., Berenguer, J., y Sanhueza, C. (2006). El Qhapaqñan entre Atacama y Lípez. Intersecciones en Antropología, (7), 217-234.

Nielsen, A. E., Angiorama, C. I., y Ávila, F. (2017). Ritual as Interaction with Non-Humans: Prehispanic Mountain Pass Shrines in the Southern Andes. En S. A. Rosenfeld y S. L. Bautista (Eds.), Rituals of the past: prehispanic and colonial case studies in Andean archaeology (pp. 241-266). Boulder, EE.UU: University Press of Colorado. doi: dx.doi.org/10.5876/9781607325963.c011

Núñez, L. (1976). Geoglifos y tráfico de caravanas en el desierto chileno. En H. Niemeyer (Ed.), Homenaje al Dr. R. P. Gustavo Le Paige (pp. 147-201). Antofagasta, Chile: Universidad del Norte.

Orgaz, M., y Ratto, N. (2013). Fragmentos del pasado en la ocupación incaica del oeste tinogasteño (Catamarca). En N. Ratto (Ed.), Delineando prácticas de la gente del pasado: los procesos socio-históricos del oeste catamarqueño (pp. 311-333). Ciudad Autónoma de Buenos Aires, Argentina: Sociedad Argentina de Antropología.
Pimentel, G. (2009). Las huacas del tráfico. Arquitectura ceremonial en rutas prehispánicas del desierto de Atacama. Boletín del Museo Chileno de Arte Precolombino, 14(2), 9-38. doi: dx.doi.org/10.4067/ S0718-68942009000200002

Pimentel, G., Ugarte, M., Gallardo, F., Blanco, J. F., y Montero, C. (2017). Chug-Chug en el contexto de la movilidad internodal prehispánica en el desierto de Atacama, Chile. Chungará, 49(4), 483-510. doi: dx.doi. org/10.4067/S0717-73562017005000102

Raffino, R. A. (1991). Poblaciones indígenas en Argentina. Urbanismo y proceso social precolombino. Ciudad Autónoma de Buenos Aires, Argentina: Tipográfica Editora Argentina.

Raffino, R. A. (1995). Inka road research and Almagro's route between Argentina and Chile. Tawantinsuyu, 1, 36-45.

Raffino, R. A. (2004). El Shincal de Quimivíl. En R. Raffino (Ed.), El Shincal de Quimivil (pp. 22-43). San Fernando del Valle de Catamarca, Argentina: Editorial Sarquís.

Raffino, R. A., Alvis, R., Manzo, A., y Toddere, M. M. (1994). Arqueología Inka cordillerana y la expedición de Almagro. Revista del Museo de Historia Natural de San Rafael (Mendoza), 13(1/4), 196-199.

Raffino, R. A., Moralejo, R. A., y Gobbo, D. (2008). El dominio Inka en la Sierra de Zapata (NOA). Investigaciones y Ensayos, 56, 309-332.

Raffino, R. A., Moralejo, R. A., y Gobbo, D. (2010). Vialidad incaica en la provincia de Catamarca (Noroeste argentino). Inka llaqta, (3), 133-159.

Ratto, N. (2015). Vivencias, acciones y resultados del quehacer arqueológico en el oeste de Tinogasta (Catamarca, Argentina). Corpus. Archivos virtuales de la alteridad americana, 5(2), 1-19. doi: dx.doi.org/10.4000/ corpusarchivos.1504

Ratto, N., y Boixadós, R. (2012). Arqueología y Etnohistoria. La construcción de un problema de investigación (Abaucán, Tinogasta, Catamarca). Memoria Americana. Cuadernos de Etnohistoria, 20(2), 187-220. Recuperado de http://ppct.caicyt.gov.ar/index.php/ memoria-americana/article/view/2039

Ratto, N., y Orgaz M. (2019). Los sitios Río del Inca-Uhle y Río del Inca-Lucke en el contexto arqueológico regional del oeste tinogasteño (Catamarca, Argentina). En T. Costa da Silva (Ed.), A. Laguens, M. Bonnin y B. Marconetto (Comp.), Libro de Resúmenes XX Congreso Nacional de Arqueología Argentina: 50 años de arqueologías (pp. 451-452). Córdoba, Argentina: Facultad de Filosofía y Humanidades, Universidad Nacional de Córdoba. 
Sempé, M. C. (1973). Últimas etapas del desarrollo cultural indígena (1480-1690) en el Valle de Abaucán, Tinogasta. Revista del Museo de la Plata, 50(8), 3-46.

Sempé, M. C. (1976). Contribución a la arqueología del Valle de Abaucán, departamento de Tinogasta, provincia de Catamarca (tesis de Doctorado $\left.N^{\circ} 346\right)$. Facultad de Ciencias Naturales y Museo, Universidad Nacional de La Plata, La Plata, Argentina.

Strube Erdmann, L. (1958). La ruta de Don Diego de Almagro en su viaje de exploración a Chile. Revista de la Universidad Nacional de Córdoba, (1), 269-293.

Strube Erdmann, L. (1963). Vialidad Imperial de los Incas. Serie Histórica, (33), 1-113.

Tarragó, M., Marchegiani, M., Palamarczuk, V., y Reynoso, A. (2017). Presencia del Inca en Yocavil (Catamarca, Argentina). Integración en la diversidad. Boletín del Museo Chileno de Arte Precolombino, 22(1), 95-117. doi: dx.doi.org/10.4067/S0718-68942017005000202

Tilley, C. (1994). A Phenomenology of Landscape: Places, Paths and Monuments. Oxford, Reino Unido: Berg Publishers.

Trombold, C. D. (1991). An introduction to the study of ancient New World road networks. En C. D. Trombold (Ed.), Ancient road networks and settlement hierarchies in the New World (pp. 1-10). New York, EE.UU.: Cambridge University Press.

Uhle, M. (1912). Las relaciones prehistóricas entre el Perú y la Argentina. En R. Lehmann-Nitsche (Ed.), Actas del XVII Congreso Internacional de Americanistas (pp. 509-540). Ciudad Autónoma de Buenos Aires, Argentina: Imprenta de Coni hermanos.
Vera, J. P. (1950). Catamarca y las ciudades de Londres. Publicaciones de la Sociedad Argentina de Americanistas, 1(1). Ciudad Autónoma de Buenos Aires, Argentina: Imprenta y Casa Editora Coni.

Vitry, C. (2000). Aportes para el estudio de caminos incaicos. Tramos Morohuasi - Incahuasi. Salta, Argentina. Salta, Argentina: Editora Gofica.

Vitry, C. (2002). Apachetas y Mojones, marcadores espaciales del paisaje prehispánico. Revista Escuela de Historia, 1(1), 179-191. Recuperado de http://www. maam.gob.ar/files/pdf/pdf_plumero/25/1.pdf

Vitry, C. (2004). Propuesta metodológica para el registro de caminos con componentes Inkas. Revista Andes, (15), 213-250. Recuperado de http://www.redalyc.org/articulo.oa?id=12701507

Vitry, C. (2007). La ruta de Diego de Almagro en el territorio argentino: un aporte desde la perspectiva de los caminos prehispánicos. Revista Escuela de Historia, 1(6), 325-360. Recuperado de http://www.scielo.org.ar/scielo. php?script=sci_arttext\&pid=S1669-90412007000100016

Weiser, W. (1925-1926). Diario de Viaje y Fotografías de la VIII ${ }^{\circ}$ Expedición Arqueológica Benjamín Muniz Barreto a la Provincia de Catamarca. Archivo de la División Arqueología del Museo de La Plata, La Plata, Argentina. Inédito.

Wynveldt, F., Ferrari, N., y López, L. (2017). El valle de Hualfín como paisaje de conflictos: un acercamiento desde el "Gran Alzamiento Diaguita". Memoria Americana. Cuadernos de Etnohistoria, 25(1), 13-30. Recuperado de http://ppct.caicyt.gov.ar/index.php/memoria-americana/ article/view/8542 